\section{sciendo}

\section{Management Consulting Journal}

Volume 1.1 | June 2018

DOI: $10.2478 / \mathrm{mcj}-2018-0005$

ISSN: 2631-987X

(C) Dr. David M Biggs. This is an open access article licensed under the Creative Commons AttributionNonCommercial-NoDerivs License (http://creativecommons.org/licenses/by-nc-nd/3.0/).

\title{
Becoming a Consultant
}

\author{
Dr. David M Biggs, University of Gloucestershire
}

\begin{abstract}
A number of different authors have highlighted the need for postgraduate students to be work ready for a career in consulting. This paper examines a cohort of $21 \mathrm{MSc}$ students from a UK-based University and how they addressed this issue through an assignment geared up towards this aim. The completed assessments ranged in terms of the strategies the students used to assess their development needs for a career in consultancy. Strategies used consisted of: competency analysis, SWOT analysis, psychometric tests, use of the British Psychological Society consultancy cycle (from the Qualification in Occupational Psychology) and use of consultancy cycles from other sources. Interestingly there was a lack of consistency between students in terms of what strategies they chose to be future consultants. This research is useful because it systematically demonstrates which strategies may be used by postgraduates to identify the skills and behaviours they need for a consultancy career.
\end{abstract}




\section{Introduction}

On completion of their first degree countless students want to embark on a career in consulting as it is a challenging but worthwhile venture. Nevertheless, consulting is a competitive industry. Inside Careers (2018) in partnership with the Management Consultancies Association (MCA) and the Institute of Consulting (IC) state that graduates must have a strong academic background with a minimum of an upper second-class Honours degree or equivalent to have a chance of embarking on a career in consulting. Also needed are good interpersonal skills and a whole range of different behaviours such as: analytical capability, leadership, resilience, communication, and technical skills (Inside Careers, 2018). Indeed, many students embark on a postgraduate degree that may help them develop these additional behaviours and skills. Universities have capitalised on this and produced postgraduate programmes that encourage a student's employability.

In the 1950s, consultancy firms recruited the best and the brightest talent from the Business Schools who were graduating with a Master's degree in Business Administration (MBA). This practice has changed somewhat nowadays and a variety of professionals from engineers through to occupational psychologists go into the consultancy field (Biggs, 2010). This is due to the attractiveness of the career not only in terms of variety of work but also in providing a real chance to practice knowledge learnt from University in a variety of organisations and businesses. Indeed, consulting gives you privileged access to small, large, public sector and private sector organisations.

\section{Skills and Behaviours Needed as a Consultant}

The skills and behaviours needed for a consultancy role are essential to develop to be successful as a consultant (Appelbaum, 2004). Skills can be taught and can range widely in consultancy practice. They can range from the so-called soft skills like interpersonal communication through to more technical skills such as project management or data modelling skills. This is obviously dependent on what type of role and work a graduate wants to go into and how they can add value to their client using their own specific discipline. So, identifying skills as a potential consultant is essential in gaining employment. Identifying skills can be done fairly simply using a tool such as a Strengths, Weaknesses, Opportunities and Threats (SWOT) Analysis. Or it can be further augmented by learning more specific skills sets either from a technical side such as PRINCE2 Project Management or through specialist qualifications in consultancy.

Skills are important in consulting but as Inside Careers (2018) reminds us, so are behaviours such as interpersonal skills. Occupational Psychologists work in analysing the behaviours that are important to good employee performance. Behaviour is not a theoretical construct but observable through evidence. It is what an individual "says" or "does" or the opposite, what they "don't say" or "do" when something is expected of them. These behaviours are often put together as a competency but several competencies often form a competency framework linked with effective or superior performance (Ballantyne \& Povah, 2004). A competency framework should ideally 
encompass all of the behaviours necessary for effective performance in a particular job role (Bowler and Woehr, 2006).

Two competency frameworks useful in examining the behaviours needed for effective performance as a consultant are the International Council of Management Consulting Institutes $(\mathrm{ICMCl})$ Certified Management Consultant $(\mathrm{CMC})$ competence framework and my own eight consultancy competency framework (Biggs, 2010). The ICMCI CMC competence framework has eight competencies in total, clustered into three broad themes of Business Competence, Technical Competence and Values, and Behaviour Competence (see Figure one). Interestingly, this framework combines both skills such as analytical skills and behaviour.

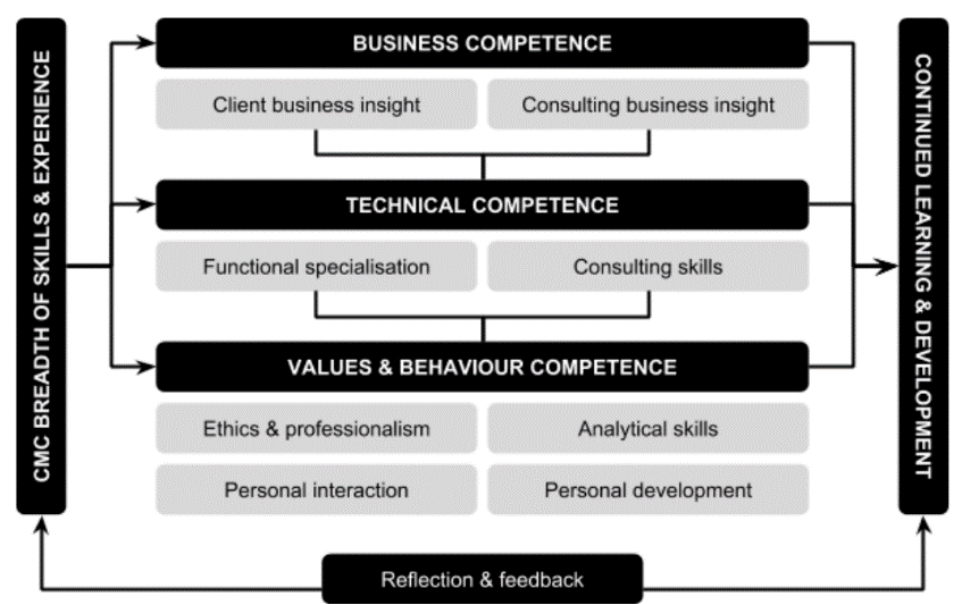

Figure One: Certified Management Consultant Competence Framework (ICMCl, 2014)

Other approaches are more purist in terms of separating behaviours and skills. Skills as mentioned earlier can be developed, whereas behaviours are more innate and are harder to change so occupational psychologists often separate the two (Biggs, 2010). In terms of the eight consultancy competency framework, this utilised two job analyses from consultancy firms and a meta-analysis of the competency framework literature (Woehr and Arthur, 2003).

Both of these competency frameworks have many similarities. Either of these frameworks, or others from specific consultancy firms, can be used to examine a person's repertoire of behaviours. This can then lead to an examination of those behaviours at an individual level leading to a list of development needs. Biggs (2010) is probably more apt for entry level consultants as it is meant for a graduate market concentrating on building up behaviours through experience performing activities. The ICMCI framework is good for a professional market as it is orientated towards the Certified Management Consultant qualification and develops through stages all geared towards improving consultancy competence through initially developing a client business insight, through to delivering achievable and sustainable results through personal interaction and development. 
Given that there are academic sources of information directly geared towards the graduate or postgraduate seeking a career in consulting, this paper was interested in what students actually do, when given the opportunity to assess themselves ready for a career in consulting. This competency framework is shown in Figure two.

Figure two.

Communication

The extent to which an individual conveys oral and written information and responds to questions and challenges

Influencing others

The extent to which an individual persuades others to do something or adopt a point of view in order to produce desired results and takes action in which the dominant influence is one's own convictions rather than the influence of others' opinions

Organising and planning

The extent to which an individual systematically arranges his/her own work and resources as well as that of others for efficient task accomplishment; and the extent to which an individual anticipates and prepares for the future

\section{Problem solving}

The extent to which an individual gathers information understands relevant technical and professional information; effectively analyses data and information; generates viable options, ideas, and solutions; selects supportable courses of action for problems and situations; uses available resources in new ways; and generates and recognises imaginative solutions

Teamwork and consideration of others The extent to which an individual considers the needs of others, participates as a member of a group and is aware of the impact and implications of decisions relevant to others

Leadership

The extent to which an individual takes on the responsibility for providing focus to a team and develops members of that team

Drive

The extent which an individual originates and maintains a high activity level, sets high performance standards and persists in their achievement, and expresses the desire to advance

Tolerance for stress/uncertainty

The extent to which an individual maintains effectiveness in diverse situations under varying degrees of pressure, opposition, and disappointment

\section{Method}

- Participants

Participants were obtained from a cohort of MSc Occupational Psychology students undertaking a consultancy skills practice module. All 21 students had submitted assignments creating a 5,000 word comprehensive portfolio critically analysing and reflecting on their existing skills and any gaps to be addressed going forward as a consultant. Students had volunteered their work to be assessed by the programme team and the external examiner. Confidentiality and anonymity was assured as the analysis of the data would not reveal any specific participant details.

\section{- Materials}

The materials available for the purposes of this research included the portfolios written by each individual participant, group PowerPoint presentations and feedback from the external consultants involved in the groups presentation, external examiner and programme team.

\section{- Design}

The design was quantitative in that content analysis was used to categorise the strategies of the students in preparing for a career in consulting. This methodology has been used in other similar studies (Duriau, Reger, \& Pfarrer, 2007).

\section{- $\quad$ Procedure}

The assignment material relevant to this research was gathered and categorised in terms of types of materials available. While the PowerPoints and video materials were considered, the portfolio assignments were the most relevant source of material for the study. These were analysed in terms of their content, which is detailed below in our results section.

\section{Results}

The results of the study demonstrated that the participants adopted a number of different strategies for analysing themselves in preparation for a career in consulting. Table A exhibits the main strategies employed. The most common strategy was use of the SWOT analysis with 14 of the 21 students completing this on themselves. Competencies were also employed with ten students assessing their behaviours. All but four students had used a consultancy cycle to illustrate how they could develop. Interestingly, the main source of this came from the stage 2 qualification in occupational 
psychology (QOP) by the British Psychological Society. However, other sources (Biggs, 2010; Block, 2011; Cockman, Evans, \& Reynolds, 1992; O'Mahoney \& Markham, 2013; Sabari, 1977; Stevens \& Campion, 1994) were used looking at the consultancy cycle either separately or in combination with the QOP consultancy cycle. A surprising strategy was seen with six of the participants, who used psychometric instruments as feedback for their assessment of their development needs.

Some of the strategies excluded from Table A were used feedback on previous consulting based assignments completed by two participants. And one student innovatively used the Johari model of feedback to analyse themselves from their own perspective and the perspective of others (Luft and Ingram, 1955).

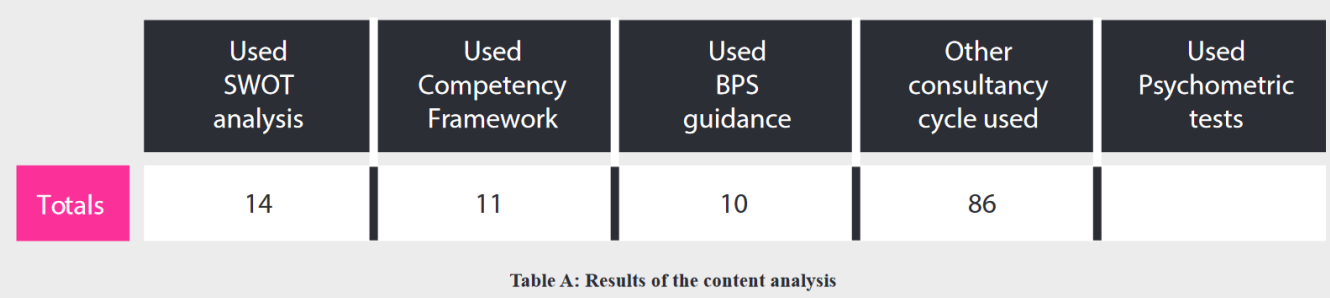

\section{Discussion}

The world of consulting is fascinating and offers a stimulating career. Students are attracted to it as they can develop themselves as professionals and occupational psychologists are no exception to this. The identification of skills and behaviours is arguably the first step to take in this endeavor. Universities keen to improve the employability of their students have encouraged this practice. Indeed, postgraduate degrees often have a consultancy skills or professional skills module. This study specifically examined which strategies students would use to prepare themselves for a career in consulting. Interestingly, a range of strategies were used.

The SWOT analysis was by far the most common method that students used to assess their development needs. Not all the participants completed a SWOT analysis and those that did not tended to use an alternative, such as a competency framework. The competency framework was used by half of the sample who demonstrated their ratings of their behaviour in a systematic way (Biggs, 2010). The six students that did not use a SWOT or competency framework relied on reflective practice to assess their development needs.

A consultancy cycle approach was used by all but 4 of the students. The most common consultancy cycle used was from the British Psychological

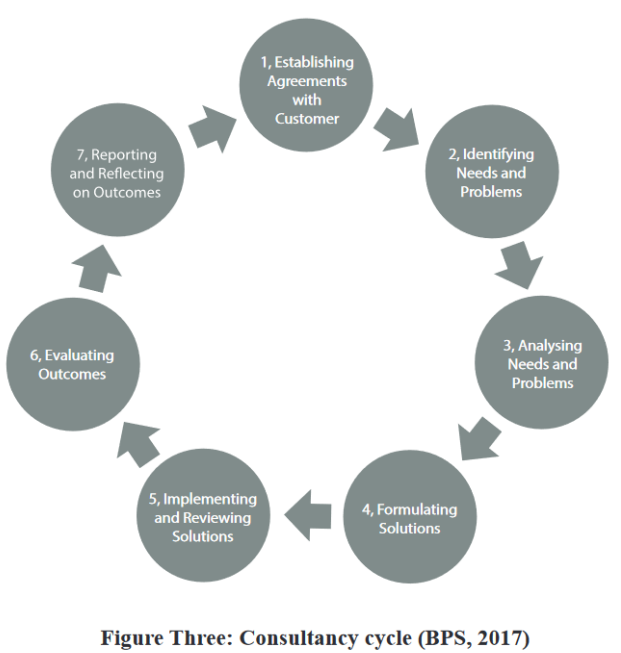


Society's QOP doctorate qualification (BPS, 2017. The outline of which is given in were all wanting to become occupational psychologists. The rating of this was also relatively easy to grasp as being either acceptable or non-acceptable (See Table B). The consultancy cycle was used to illustrate what gaps in the participants skills, behaviours and knowledge they had. This was useful in assessing their potential development needs, that they could work on either while at University or in their entry level employment.

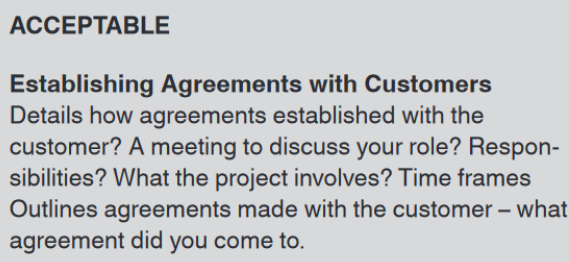

Identifying Needs and Problems

Details how needs and problems were identified.

For example through discussions with the customer, meeting with stakeholders, a needs analysis. Outlines what the needs and problems were.

Analysing Needs and Problems

Outlines how the needs and problems were analysed such as through analytical tools, analysis of data etc.

\begin{abstract}
Formulating Solutions
Based on what you have found so far from the analysis what are the potential solutions, how were these formulated? Based on what information? Literature?
\end{abstract}

Implementing and Reviewing Solutions This is the implementation stage. What was implemented and how? How was this reviewed to ensure what you implemented is working? Were any changes made?

Evaluating Outcomes

How was an evaluation conducted to ensure you met the project outcomes agreed with the customer? What was found? Sometimes a client will not pay for an evaluation, but you can evaluate whether the outcomes agreed with the customer have been met and explain how you have evaluated this.

Reporting and Reflecting on Outcomes Reporting on outcomes may involve the writing of a report, a presentation to the client etc. Reflecting involves you reflecting on the outcomes of the project, what you would change if faced with a similar project in the future, any issues you had, what worked well.

\section{NOT ACCEPTABLE}

Establishing Agreements with Customers Provides insufficient detail on how the agreements were formed, what the agreements were etc.

Identify Needs and Problems

Lacks detail of how the need and problems were identified - may just outline what the needs and problems are.

\section{Analysing Needs and Problems}

Does not outline how the needs and problems were analysed. May just identify the outcome of the analysis.

\section{Formulating Solutions}

Does not outline how solutions formulated but may just outline what the solutions are. Lacks details on what information was used to formulate the solutions.

Implementing and Reviewing Solutions

Not enough detail provided on what was implemented how and why. May outline the implementation but not detail how it was reviewed, whether any changes were made.

\section{Evaluating Outcomes}

Lacks detail of evaluation or the candidate is not able to conduct an evaluation due to the client not wanting one.

Reporting and Reflecting on Outcomes Lacks sufficient detail. For example may state they have developed a report but not what was reported. May outline the reporting aspect but not the reflecting on outcomes.

Psychometric tests were also used by a small number of the sample to illustrate areas that are often hidden but can be revealed through psychometric evaluation. This information did supplement the strategies used by the students in gaining skills necessary to become a consultant by providing scientific information about personality traits, preferences and even their team roles. Again, given the sample consisted of 
trainee occupational psychologists it is not surprising that they used psychometric evaluation.

\section{Conclusions}

This paper extends current knowledge in the area of consulting by exploring the strategies employed by postgraduate students in preparing themselves for a career in the industry. Students used a mixture of behavioural and skills techniques to determine what they needed to develop to become a consultant. Behavioural techniques almost exclusively consisted of using competency frameworks to investigate their prior actions in terms of what contributed towards prior achievements. In terms of examining skills, the SWOT technique was used examining the strengths, weaknesses, opportunities and threats that the individual faced. Most students also used a consultancy cycle to illustrate what development needs they may have. The consultancy cycle of choice was predominately from their professional body. However, other sources of information put forward by academics were used either instead of the professional body's cycle or as a compliment to this progression. More advanced students also used psychometric testing to look at their personality traits or team orientation. Again, this knowledge was intertwined with the other evidence gathered leading to a thorough assessment of the students development needs for a consultancy role. 


\section{References}

Appelbaum, S. H. (2004), Critical Success Factors in the Client-Consulting Relationship. Journal of American Academy of Business, 4(1/2), 184-191.

Ballantyne, I. and Povah, N. (2004), Assessment \& Development Centres. Hants: Gower Publishing Ltd

Biggs, D. M. (2010). Management Consulting: A guide for students. London: Cengage Learning.

Block, P. (2011). Flawless consulting: A guide to getting your expertise used (3rd ed). San Francisco: Pfeiffer.

Bowler, M.C. and Woehr, D.J. (2006), A Meta-Analytic Evaluation of the Impact of Dimension and Exercise Factors on Assessment Center Ratings. Journal of Applied Psychology, 91(5), 1114-1124

British Psychological Society (BPS) (2017) Qualification in Occupational Psychology (Stage 2) Candidate Handbook Retrieved on 31/05/2018 from https://www.bps.org.uk/sites/bps.org.uk/files/Qualifications/QOP\%20Candidate $\% 20 \mathrm{Han}$ dbook\%20(updated).pdf

Cockman, P., Evans, B., \& Reynolds, P. (1992). Client-centred consulting : A practical guide for internal advisers and trainers. London: McGraw-Hill Book.

Duriau, V., Reger, R., \& Pfarrer, M. (2007). A content analysis of the content analysis literature in organization studies. Organizational Research Methods, 10(1), 5-34.

Inside Careers (2018) Management Consultancy. Retrieved on 30/05/2018 from http://www.insidecareers.co.uk/professions/management-consultancy

International Council of Management Consulting Institutes (2014) CMC Certification Scheme Manual Appendix 1 - CMC $®$ Competence Framework. Retrieved on 30/05/2018 from https://www.cmcglobal.org/sites/default/files/public/CMC/appendix_1__specimen_cmc_competence_framework_cmc002.pdf

Luft, J. \& Ingram, H. (1955), The Johari Window: A graphic model of interpersonal awareness. Proceeding of the Westem Training Laboratory in Group Development. Los Angeles: University of California Extension Office.

McKenna, C.D. (2006), The World's newest profession: management consulting in the twentieth century. New York: Cambridge University Press

O'Mahoney, J. and Markham, C. (2012). Management Consulting 2nd Edition Oxford: Oxford University Press 
Sabari, R. E. (1977), Management Consulting, A Guide To The Profession. Journal of Marketing Research, 14(3), 422.

Stevens, M. J., \& Campion, M. A. (1994). The knowledge, skill, and ability requirements for teamwork: Implications for human resource management. Journal of management, 20(2), 503-530.

Sturdy, A., Wylie, N., and Wright, C. (2013). Management Consultancy and Organizational Uncertainty: The Case of Internal Consultancy. International Studies of Management \& Organization, 43(3), 58-73.

Woehr, D.J. and Arthur Jr., W. (2003), The Construct-Related Validity of Assessment Center Ratings: A Review and Meta-Analysis of the Role of Methodological Factors. Journal of Management; 29(2), p231-258 